\title{
A Capabilities Approach to Food Choices
}

\author{
Karolina Gombert ${ }^{1,2}$ (D) - Flora Douglas ${ }^{1}$. \\ Sandra Carlisle ${ }^{1} \cdot$ Karen McArdle $^{2}$
}

Accepted: 29 May 2017 / Published online: 16 June 2017

(C) Springer International Publishing Switzerland 2017

\begin{abstract}
I question the notion of food choice and consider how much food choice someone living on low income actually has. In my fieldwork, it became clear that food choices, and hence one's nutritional and health state, cannot be viewed in separation from the participants' individual stories and the complexities of their lives. Daily routines, financial situation, and food accessibility have an impact on people's food choices. In realising this, I found Amartya Sen's $(1979,1985)$ capabilities approach useful, which moves beyond food entitlements. More specifically, a health capabilities approach as introduced by Venkatapuram $(2007,2011)$ and the association made between health and capabilities by others (e.g. Ruger Yale Joural Law Humanities 18 (2): 3, 2003) views health as the combination of the influence of socioeconomic structures, as well as personal agency resulting in choices. I present the main learnings from viewing Foodways and Futures through the 'capabilities lens' and thus view food choices as the combination of the complex interrelations between socio-economic structures and agency.
\end{abstract}

Keywords Young people · Food poverty C Capabilities approach · Amartya Sen · Choice · Action research $\cdot$ Vulnerable groups

\section{Project Background}

The Foodways and Futures project (2013-2016), as part of the "Pathways to a Healthy Life" theme at the University of Aberdeen, is an interdisciplinary project, combining education, sociology, public health and nutrition. An unpublished pilot study, conducted with young

Karolina Gombert

KarolinaGombert@gmail.com

1 Institute of Medical Sciences, Rowett Institute, Foresterhill Campus, University of Aberdeen, Aberdeen, UK

2 School of Education, Old Aberdeen, University of Aberdeen, Aberdeen, UK 
people who had previously been homeless and were temporarily accommodated by a charitable youth organisation in the North East of Scotland suggested that young people (16-25) experiencing homelessness and social deprivation were struggling to consume sufficient amounts of healthy foods according to UK nutritional guidelines (Perry 2013). The Foodways and Futures project was developed to investigate the lived experiences of the young people accommodated by the same organisation, to explore how, why and in what context they make their food choices. The study was based at the same charitable youth organisation, which accommodates up to 86 young formerly homeless people at seven housing sites across the North East. I combined action research and ethnography as mutually beneficial research approaches. Four different research methods were employed: participant observation at three of the housing sites, interviews, as well as a peer researcher group of young people and photovoice as more participatory approaches.

\section{Research Methods and Participant Recruitment}

As noted above, multiple qualitative methods were used. Members of staff as well as young people accommodated or affiliated with the organisation took part in the study. Table 1 shows the participant numbers for each method respectively. Participant observation took place over a period of ten months at three of the organisation's housing sites, as well as at a community centre. These housing sites were categorised as rural, semi-rural and city, and thus provided a range of different contexts, as well as some differences in working structures across the sites. During the ten months fieldwork, $552 \mathrm{~h}$ of observation hours were spent at the housing sites over 69 days, based on an average of eight hours observation each day. Fieldwork also included another 14 days (112 h) observation outwith the ten months study period. The fieldwork required participation in the daily life of the young people living in the organisation: visiting them, cooking with them, helping them with household cleaning, helping them with job applications, going shopping with them, taking part in social and physical activities such as going for walks, watching TV together, talking over tea, and accompanying them on visits to the doctor. This work represented an extensive commitment to the participants, and intensive full time study of the participants' living environment. ${ }^{1}$ The study was approved by the Ethics Committee of the Rowett Institute of Nutrition and Health.

Individual in-depth semi-structured interviews were conducted with young people as well as members of staff. Five individual in depth interviews were conducted with young people, five with members of staff, and one with a board member. Two focus groups with young people also contributed to the data. This comparatively small number of interviews was found to be adequate, in light of the substantial amount of data collected during the participant observation phase, as topics and themes started to repeat. The research also involved many hours work with a core researcher group of participants. Although data from the participatory element of our research process did not primarily focus on food decision making or practices, fieldnotes by one young peer researcher did look into food choices and have informed this paper. It is also important to note that some participants informed more than one research method. There were no direct, e.g. monetary, rewards for participation. This paper is not a direct analysis of any of the research methods, but instead, provides a philosophical stance to

\footnotetext{
${ }^{1}$ This intensive fieldwork with a vulnerable group generated a number of ethical challenges and dilemmas which are documented elsewhere (Gombert et al. 2015).
} 
Table 1 Participant numbers HS = housing site, $\mathrm{CC}=$ Community Centre

\begin{tabular}{|c|c|c|c|c|c|}
\hline Methods & HS1 & HS2 & HS3 & $\mathrm{CC}$ & Other* \\
\hline \multicolumn{6}{|l|}{ Young People } \\
\hline Observation & 4 & 1 & 7 & l & / \\
\hline Interviews & / & 3 & 1 & l & 1 \\
\hline Researcher Group & / & 1 & 7 & l & / \\
\hline Researcher notes & / & 1 & l & l & / \\
\hline Focus groups & / & 1 & 4 & 10 & / \\
\hline Photovoice & 3 & 1 & 4 & 9 & / \\
\hline Informal conversation & 3 & 5 & 7 & l & / \\
\hline \multicolumn{6}{|l|}{ Members of staff } \\
\hline Observation & 3 & 2 & 4 & 19 & \\
\hline Interviews & 1 & / & 2 & 2 & l \\
\hline Informal interviews & 1 & / & 1 & 4 & 7 \\
\hline \multicolumn{6}{|l|}{ Board member } \\
\hline Interviews & / & l & 1 & l & 1 \\
\hline Total & 15 & 15 & 37 & 44 & 9 \\
\hline
\end{tabular}

* Other refers to other housing site or not being based at either HS or CC

how the contradictions that became apparent through employing each of the research methods can be viewed.

\section{Food Poverty and Health Inequalities in Scotland}

Simply put, poverty means living below the minimum income level. In 2014-15, 800,000 people or $15 \%$ of the Scottish population, were living in poverty. Of those, 160,000 were children, 470,000 were adults of working age, and 160,000 were pensioners (The Scottish Government 2015). Nevertheless, household level data do not exist, and foodbank statistics only give an indication of the extent of the problem. In Scotland, Trussel Trust figures show that 133,726 people received emergency food aid provision in 2015/16. The 1996 Scottish Diet Action Plan recognised that food poverty is a public health issue. Current figures and future predictions for population health point to health inequalities across the Scottish nation (Audit Scotland 2012). The 2012 Audit Scotland report shows health differences between least and most deprived areas. For example, the life expectancy for women is 84.2 years and for men 81 years in the least deprived areas, compared to 76.8 years for women and 70.1 years for men in the most deprived areas. Similarly, according to the latest 'Health and Community Care' figures by the Scottish Government in 2009 (2010:5), in the most deprived 10\% of areas, the under 75-year-old death rate was 680 per 100.000 people in comparison to 185 per 100.000 people in the least deprived $10 \%$ of areas. The Scottish Government report on 'Preventing Overweight and Obesity' (2010) states that by 2030, over $40 \%$ of the Scottish population is predicted to be obese. Consequently and concurrently, diabetes and cardiovascular diseases are on the rise; and obesity is also connected to rising number of people being diagnosed as depressed (The Scottish Government 2010; Donnelly 2007:9). It has been estimated that, from 2007 to 2012, malnutrition contributed to the deaths of at least 487 people in Scotland (McKelvie 2012). On the other hand, Scotland throws away 600,000 t of food and drink from households every year, which mostly could have been eaten. This waste costs Scotland over $£ 1$ billion annually, equivalent to $£ 460$ for the average household (Love Food Hate Waste 2016). This is not to say that poorer people should eat what others throw 
away, but it goes to show a somewhat unbalanced food distribution, which is surely not the case in Scotland only. Nevertheless, the Scottish government (2015a) has measures in place to help support food aid programmes, currently funded with $£ 1$ million; and the NHS explicitly notes that "health inequalities are strongly associated with socio-economic inequalities, and are increasing in Scotland. The causes of death increasingly responsible for mortality inequalities are suicide, alcohol and drug-related violence, all with clear social causes" (National Health Service, NHS 2014). It is questionable whether the support of food aid programmes actually addresses socially patterned health conditions.

In particular, food choice has long been recognised as involving psychological, social, cultural, economic, and biological forces (Bisogni et al. 2002; Bourdieu 1986/1973). Bourdieu (1984/1973) argued that food choices are strongly influenced by one's social status. Wilkinson and Picket (2010) have since shown a strong relationship between health and social determinants with regards to inequality. Based on their analysis of the Organisation for Economic Cooperation and Development's (OECD) member countries and individual US states they conclude that richer people, on average, tend to be healthier and happier than poorer people in the same society. Also the Marmot et al. (2010) makes it clear that the link between social conditions and health must become a focus in health concerns. Donald (2009:240) argues that, "being in a lower social class or having few years in formal education is more dangerous to one's health than having high cholesterol or exercising little". Especially for so called 'hard to reach', 'vulnerable', or 'at risk' groups, the factors influencing food choices may be complex. This is because issues of ability to afford healthy foods, eating for fullness rather than nutritional value, reliance on day centres for food, irregular lifestyles, and lack of knowledge about healthy eating are likely to be more prevalent (Coufopoulus and Mooney 2012; Davison et al. 2015). Also the World Health Organisation (WHO) Commission on Social Determinants of Health emphasises that health inequalities result from the organisation of modern societies through their economic, social and political policies and practices (World Health Organisation, WHO 2005). Similarly, Barton and Grant (2006) developed 'a health map for the local human habitat' to explain the relationship between health and the physical, social and economic environment. The above goes to show that while the influence of the social, cultural and economic environment on health is widely recognised, inequalities persist.

For example, Friel et al. (2015), in their review of the evidence of actions which are aimed at addressing the social determinants of inequities in healthy eating, find that the majority of such evidence focused on individual level factors as well as population averages. This type of evidence may help to achieve short term successes, but yet misses the problem's core: "the underlying unequal distribution of factors that support the opportunity to eat a healthy diet" (Friel et al. 2015:84). In fact, food insecure people may not seek help from food aid providers (Lambie-Mumford et al. 2014; Douglas et al. 2015a, b). This unclear picture of the number of people in food poverty in the UK contributes to a growing concern of an emerging public health crisis of people not being able to nourish themselves (Lambie-Mumford et al. 2014; Douglas et al. 2015a, b).

\section{Purpose and Aims of this Paper}

The disconnect between people's realities, socio-economic structures and public health efforts, raises questions of what food choice, in particular for vulnerable groups such as the young people in my study, really means. Does it mean measuring their lack of knowledge of healthy 
foods (Dowler 2008)? Or measuring a perceived attitude of not caring much and preferring to eat 'what they like' (Dowler 2008)? Dowler argues not. This paper is to understand such problems of - in particular vulnerable groups' - agency and choice in the context of the efforts and discourses surrounding food poverty in the UK. It became apparent to me, that whilst I explored choices, those are very restricted for the young people, posing the question of how much food choice there actually is for vulnerable groups. This paper addresses public health and health promotion efforts to improve nutrition, as well as the challenges I faced during fieldwork and in drawing conclusions from the work. I was influenced by Amartya Sen's capabilities approach $^{2}$ as a useful and relevant conceptual framework in order to better understand what food choice really means.

Therefore, in this paper, I illustrate the notion of food choice for vulnerable groups in light of the theoretical capabilities framework. Utilising the capabilities approach in the context of food choices allows for the consideration of structural conditions as well as positioning individuals as active agents within the realities of their own lives. At the same time, I aim to show that the capabilities approach can be help to inform a number of contexts; here, the constraint food choices of vulnerable groups. This paper is to be viewed as a theoretical and philosophical engagement with the challenges I faced during fieldwork; and at the same time, is to provide food for thought on how such challenges may be viewed. Building on Sen's (1982) and Venkatapuram's (2013) work, and expanding on these, I show that choosing health generally, and healthy food in particular, is dependent on an individual's socio-economic environment; and ultimately their capabilities to choose within that environment. This is again, within the scope of the main aim of the Foodways and Futures project: to make aware and give insight into the complex living situations of the young people, within which they make their 'food choices', or rather, within which their food choices are constraint.

\section{The Capabilities Approach}

The approach was first discussed in the early 1980s (Sen 1982); and has been influential in evaluation, social assessment, policy analysis and development since then (Lewis 2012; Robeyns 2003). The approach can be understood as a normative, moral and human rightsbased framework and as a theory of social justice. It can also be understood as an evaluation tool for individual well-being and social arrangements, a way of influencing the design of policies and proposals about social change in society, as well as a concept applied in academic discussions (Robeyns 2003; Clark 2006; Walker 2005; Lewis 2012). Some of the approach's aspects go back to the ideas of Aristotle, Adam Smith, and Karl Marx, among others (Robeyns 2003; Cockerill 2012). Sen argues that outcomes, or 'functional utilities', should not be the sole object of welfare assessments and that capabilities, things that people are free to do or be, should also be included in the overall assessment of wellbeing (Lewis 2012; Robeyns 2003). The focus should be on the quality of life, and on removing obstacles in people's lives so that there is more freedom to live the kind of life which, upon reflection, every individual finds valuable. In this, individual agency is crucial in order for people to decide for themselves on a valuable life. Someone's capability to be healthy is a function of his or her access to resources and various psycho-social capabilities that allow him or her to translate those resources into healthy behaviour and ultimately health.

${ }^{2}$ Also 'capability approach' 
The capabilities approach broadens the basic framework to explore the effects of rights, freedoms, policies and social, political and economic arrangements on people's capabilities and lives, and on people's 'well-being'. Sen points out that although freedoms are inter-related and can be mutually reinforcing (e.g. social opportunities such as education facilitate economic participation which in turn helps generate public revenue for social facilities), economic growth or consumption does not always expand a person's capabilities; social activities exist outside of the market (Carpenter 2009; Sen 2010). But the very conceptualisation of capabilities is not straight forward (Burchi n.d.). Sen does not specify the attributes of a good life, but instead, leaves the interest in specific capabilities up to the individual (Pogge n.d.). He argued that every individual should have the freedom for 'real opportunity [...] to accomplish what we value' (Sen 1992). In this sense, a good life would be a life of genuine choice, an authentic self-direction (Oxford Poverty and Human Development Initiative OPHDI n.d.). According to Sen, each person has his or her own values, but has to identify these valuable capabilities reasonably. The term 'reason to value' implies that people should select their basic capabilities and should be able to defend them. In reality, however, people might live in materially deprived circumstances, or simply have a very small informational basis, and this lack of information and capital is likely to affect their capability to reason in the first place and ultimately their choice (Robeyns 2003). But a key analytical distinction in the capabilities approach is that between the means and the ends of well-being and development. The ends have intrinsic importance, but the means are instrumental to reach the goal of increased wellbeing and development. In this, we place value and ethical importance on being able to choose for ourselves and establish an ethical guideline for people to be able to choose for themselves. The capabilities approach focuses on the importance of individual agency, as people's ability to choose and to pursue those ends of wellbeing that are valuable to them (Walker 2005). It is therefore important to always consider the value of things and processes, whether they are instrumental or intrinsic (Robeyns 2003). The capabilities approach also provides a framework for discerning whether capabilities are equally distributed (Robeyns 2003; Sen 1999). In this, Sen makes it clear that the interrelations between extrinsic resources and capabilities, and hence the actual capability, is dependent on a person's individual social characteristics such as gender and age. Sen (1999) argues for consideration of human capabilities in terms of: 'their direct relevance to the well-being and freedom of people' as well as 'their indirect role[s] through influencing social change and [...] economic production'.

\section{The Capabilities Approach and Health}

The Ottawa Charter (WHO 1986) was a public health milestone in recognising people's agency. The Charter promotes the public's health in order to enable people to increase control over and improve their health. Abel and Fröhlich (2012) describe the structural conditions approach to public health utilised in the Charter as a way of stressing the importance not only of agency; but also of structures. Socio-economic structural forces were believed to be responsible for health inequalities and individuals were understood to be able to productively influence structural conditions affecting their health through their actions (Abel and Fröhlich 2012). Since the writing of the Charter some agreement on the interactions between structures and agency has been reached (Abel and Fröhlich 2012). Yet, how exactly to enable people to act in favour of their health remains unresolved in health promotion (Abel and Fröhlich 2012). Nor does an agreed upon, precise and coherent conception of health yet exist (Venkatapuram 
2013). Within this context, Scott-Samuel and Smith (2015) draw attention to the 'utopianism' of many public health efforts and the 'confusion of values' underlying current policy commitments in trying to reduce health inequalities. They argue cogently that, in our current neoliberal system focused on economic growth leading to concentrations of wealth and power, the idea of reducing or even eradicating health inequalities on population level is 'fantastical' as this very system is dependent on and driven by inequalities (Scott-Samuel and Smith 2015).

It is now widely accepted that health is influenced by a person's socio-economic environment, which in turn influences the resources that an individual can access to be healthy (Barton and Grant 2006). Nevertheless, we lack an a priori list of resources an individual needs to be healthy (Burchi n.d.). Rather, identifying such resources depends on their object, in this case, health; and we need to look at the process of building capabilities (Abel and Fröhlich 2012). A focus on the capabilities building process would mean a clear shift in health policy from being directed by statistics to being process oriented. This practical connection between the capabilities framework and health stems from its influence in development economics which led, after reaction to the Ottawa Charter, to the creation of the Human Development Index (HDI) by the United Nations Development Programme (UNDP) in 1990 (Simon et al. 2013). HDI measures levels of national development using a composite statistic comprising of national income, education and life expectancy. While health is surely connected to other factors, the explicit inclusion of life expectancy for human development on the international agenda ascribes a central role to health for human flourishing. Literature on the connection between different aspects of health, health measurement, and capabilities is growing. Venkatapuram's (e.g. 2007, 2011, 2013) writings are particularly relevant here. According to Pritchard (2012), he makes clear that the core problem of health inequalities, (e.g. negative health outcomes due to lack of physical and economic access to healthy foods), is the relationship between health and capabilities. To him, the broader notion of fairness in society cannot be separated from health justice. In this, health is more than the absence of disease; but a 'meta-capability', as a combination of 'basic capabilities to be and do things' (Venkatapuram 2007, 2011). The metacapability of health thus creates a basis for individuals to be able to have reason to value, and hence expands on Sen's framework. Viewing health as a meta-capability also means it is dependent on the individual's socio-economic status. In this regard, Deneulin (2009) calls health a human capital. Health becomes explicitly linked to exterior factors in a person's individual environment, which means that health is much more difficult to 'activate' as a metacapability when living in poverty or marginalised circumstances.

\section{The Capabilities Approach and (Food) Poverty}

The capabilities approach, and Venkatapuram's derivative of health meta-capabilities, aim to accommodate the influence of both socio-economic structures and individual choice on health (Weaver et al. 2014), as opposed to a focus on either social structures, or individual agency. Individuals act within social structures, over which they may have little influence, and yet are seen as individual agents responsible for their own health (Weaver et al. 2014). The capabilities approach views poverty as the deprivation of capabilities. Someone can be deprived of his or her capabilities in many ways, for example by government oppression and lack of financial resources. The relationship between food intake and nutritional value is analysed by Sen (1985). Together with Drèze and Sen (1991), Sen developed the 'entitlement' analysis, which 
argues against the Malthusian idea that starvation is due to a human population outstripping its food supply. Sen and Drèze found that lack of food availability in famine zones was not the reason for starvation, which can occur where food is plentiful. They concluded that a complete theory of famine must consider other triggers, taking into account social, political and economic factors. It is thus not a question of the available resources but of whether or not individuals can access these resources (Pritchard 2012). Accessing will depend on their capabilities to do so. Capabilities - the conversion of personal income, resources and commodities into well-being and freedom, as noted above - "[depend] crucially on a number of contingent circumstances, both personal and social" (Sen 1999). Variations and instabilities in the factors which influence the relation between resources and well-being may limit food security. Daron and Drenowski (2015), among others for example, show that energy dense foods cost less per calorie than nutrient rich foods, and that people in lower income groups tend to choose the cheaper diets, which are often lacking in nutrients. By not only looking at 'command over food' but also at 'nutritional capabilities', the capabilities approach includes both the 'access' dimension of food security and the 'utilisation' dimension. ${ }^{3}$ In this, both access to resources and psycho-social capabilities are a function of social structures and people's position within them.

Underlining this utilisation dimension reveals the underlying problems of agency and choice which are particularly relevant in the context of food security of vulnerable groups. For low income groups, impacted by their financial situation and other related factors, it might be difficult to utilise their psycho-social capabilities to access healthy foods. Health as a meta-capability (which includes not being hungry, in order to be able to make informed decisions and choices) is important in order to achieve what we "have reason to value" (Sen 1985). For vulnerable groups, agency and choice might be limited, and barriers to converting resources such as education into capabilities have been recognised. These barriers include income deprivations as well as 'adaptive attitudes', since people's expressed preferences may be due to (learned) restricted agency because of discrimination or disadvantageous socio-economic positions. There may also be a 'coupling of disadvantages between different sources of deprivation' (Sen 2010). For example, the stigma of a mental illness diagnosis may have negative effects on earning a living, which may again impede the conversion of capabilities (Sen 2010). The evaluation of a public good, such as education, thus needs to take into account the ways in which social inequalities rooted in cultural or structural contexts affect people's abilities to make use of resources to enhance their capabilities (Walker 2005; Lewis 2012).

\section{Discussion: What is Food Choice Really?}

Our nutritional state is, plausibly, the result of our own food choices or what more accurately might be referred to as our consumption practices. But the factors underlying our food choices are complex. Agency, the power to practice these 'freely-made' food choices, is dependent on the social structures individuals live by. Agency, choices and social structures are hence interdependent. This also means that social structures, rights and freedoms, can shape the environment positively or negatively for people to practice their choices (Lewis 2012). In order

\footnotetext{
${ }^{3}$ The three dimensions of food security have already been defined in the 1996 World Food Summit as availability, access, and utilisation (United Nations Development Program, UNDP 2012).
} 
to explain why agency and structures do not harmoniously match, and their combination could instead be detrimental to a person's health, Abel and Fröhlich (2012) refer to Weber's work on lifestyles. According to Weber (1978), lifestyles are closely related to socio-economic status. 'Status honour' differentiates between different socio-economic groups and influences the lifestyle that seems to be a societal preconception about a particular group. What is more, lifestyles depend on consumption behaviour as opposed to what someone produces (Cockerham et al. 1993). Hence, differences between groups and their degree of status honour become visible through what groups consume. Cockerham et al. (1993) argue that health, as an instrument to be used towards an end such as work, is something 'to be consumed' as opposed to being produced. I understand this as in line with Vekantapuram's conception of health as a meta-capability. It also means that choices are not only influenced by rather uncontrollable socio-economic structures, such as governmental structures, but also by a feeling of social belonging to a particular group; and potentially by what is expected of one. This parallels Bourdieu's (1986) theories of capital interaction and habitus, which explains how an unequal distribution of material and non-material resources can lead to the reproduction of unequal life chances and a limitation of choice. Hence, the social context is a choice shaping force which influences a person's values, determinations, and hopes, within an ongoing process of socialisation (Weaver et al. 2014). When this happens, people develop what Bourdieu (1986) calls 'habitus', a habit of acting in a certain way - perceived as natural to the person or group - which leads them to prefer some choices to others; some choices thus become the norm. In other words, external social structures are internalised and turn into personal behaviours (Weaver et al. 2014). Personal agency arguably dissolves, to some extent, within the broader socio-economic context. Choices exist, within the lifestyle someone either wants to adopt or feels obliged to adopt, and yet, are influenced by capabilities to execute them (Cockerham et al. 1993). From this, in line with Pogge's (n.d.) critique of Sen's capabilities approach as being overly positivist and potentially endorsing 'naive' values, one could argue that genuine agency is an illusion. In any case, I find a dual relationship between agency and structures; in the sense that the better the pre-given structures, the more agency someone is able to execute, and hence the more choices someone can make. Conversely, the more unequal the pre-given socio-economic structures, the less agency someone is able to execute, and hence the fewer choices someone has.

In line with Scott-Samuel and Smith (2015), this poses the question to public health of how vulnerable groups are to break out of the seemingly vicious cycle of activating enough capability by means of their own agency in order to arrive at better wellbeing, and to make healthier food choices, if their agency is confined within the very same structures that also influence their health behaviour. Despite recognising the impact of social structures on individual agency, it is difficult to disentangle in what particular way social causes undermine agency. We could also imagine that an individual's choice depends upon his or her social circumstances and the identities and capabilities he or she has as a result of those circumstances, yet, it would still be a choice or an authentic choice or an autonomous choice. This is the dilemma in health promotion: ethically, people are allowed and encouraged to make their own individual and independent choices, and yet, people are expected and enjoined to make healthy, sustainable food choices, even if unable to afford this.

With regards to the operationalisation in Foodways and Futures, the capabilities approach upholding values of emancipation and empowerment, also sustains a basis for the action research rationale. At the same time, action research also creates knowledge on the operationalisation of the capabilities approach (Walker 2005). This is because in the action 
research process, we look into whether capabilities are distributed fairly; whether some people have more opportunities to convert their resources into capabilities than others, and which capabilities matter most in developing agency and autonomy for future opportunities and choices (Walker 2005). In this sense, whilst both approaches are part of the same 'value paradigm', action research gives an impetus for reflection on how the capabilities lead to (food) choices. Both approaches combined as well as on their own, support the main aim of revealing the challenges that young people are faced with.

Still, when working with young people as well as children, further issues surrounding their capability for voice and hence to make choices emerge (Lumby and Morrison 2009). Are children and young people able to make choices that will enhance their capabilities? Do they have enough knowledge and are they stable enough to know now what will benefit them in the future (Lumby and Morrison 2009)? Sen in this regard argues that children in particular may sometimes need to be denied their choices if those choices are not beneficial to their lives as an adult. Yet, who is to assess future benefits and who is to decide about denying children and young people their choices? These issues are a dilemma intrinsic to the nature of projects such as Foodways and Futures. But the understanding of capabilities may not just be an issue for children and young people, but also for adults. Al-Janabi et al. (2013) in this regard, investigated how individuals self-reported their capabilities. Via think-aloud interviews with 75 adults in the UK, the findings suggest that the "majority of participants were able to comprehend questions about their capabilities, felt able to judge what he called "capability wellbeing" and provided responses in line with this judgment' (Al-Janabi et al. 2013). But this was not the case for everyone (Al-Janabi et al. 2013).

Furthermore, whilst we become aware of the other priorities which might interfere with the decision making of vulnerable young people, doubts about vulnerable groups' potential for agency are also problematic. This is because such doubts can lead to negative judgements about vulnerable groups' capabilities to act on their own behalf, although this is counter intuitive and detrimental to the emancipatory rationale behind the capabilities approach. It is therefore crucial to communicate such dilemmas explicitly and in non-judgmental ways with colleagues, decision makers and the young people themselves. Viewing people in preconceptualised and overly judgmental terms is not genuine empowerment towards overcoming barriers to (health) capabilities and ultimately making healthy food choices.

\section{Conclusions}

Health is shaped by the chances or opportunities people have to pursue health and to be healthy, along with the choices they make relative to these chances. Life chances are a function of the resources available to connect them to larger social structures. The food choices for vulnerable groups are particularly limited, but exploring relations between socio-economic structures, agency and food choice through a capabilities lens raises awareness of the challenges in combining between them. In turn, we are able to consider structural conditions as well as the active roles of individuals in determining their health. Looking through the capabilities lens makes it clear that the route to tackling health inequalities is not only the provision and availability of resources, such as healthy foods and money, but the activation of capabilities to perform health through these resources. I hope to raise awareness of the issue of the young people's capabilities to act on their health, which need to be more the focus of public 
health practice, in order to reduce health inequalities within the inevitable constraints of our current neoliberal political and economic system.

In line with Abel and Fröhlich (2012) I suggest that people's capabilities to be genuinely active for their health be considered more as a key concept in public health. This approach will take into consideration the complexities of people's lives and their socio-economic environments; especially for vulnerable groups. In the case of Foodways and Futures, the way forward for us is to listen to young people, and enable them to decide what they need to be healthy. Only if what young people have reason to value makes sense to them, and also fits in with their lifestyles will they genuinely be able to expand their capabilities. In this sense, then, food choice is what makes subjective sense to individuals.

Acknowledgements This paper has evolved from a 3.5 years PhD studentship in Applied Health Sciences at the University of Aberdeen, entitled Foodways and Futures, under the supervision of Dr. Flora Douglas, Dr. Sandra Carlisle, Dr. Karen McArdle and Prof Geraldine McNeill. The charitable youth organisation, The Aberdeen Foyer, is the community partner in the project. This work was supported by the by the Scottish Government's Rural and Environment Science and Analytical Services Division (RESAS).

Compliance with Ethical Standards All procedures performed in studies involving human participants were in accordance with the ethical standards of the institutional and/or national research committee and with the 1964 Helsinki declaration and its later amendments or comparable ethical standards.

The study has been approved by the Ethics Board of the Rowett Institute of Nutrition and Health at the University of Aberdeen.

\section{References}

Abel, T., and K. Fröhlich. 2012. Capitals and capabilities: Linking structure and agency to reduce health inequalities. Social Science \& Medicine 74 (2): 236-244.

Al-Janabi, H., T. Keeley, P. Mitchell, and J. Coast. 2013. Can capabilities be self-reported? A think aloud study. Social Science \& Medicine 87: 116-122.

Audit Scotland 2012. 'Health inequalities in Scotland.' Last accessed March $11^{\text {th }} 2017$ at http://www.auditscotland.gov.uk/docs/health/2012/nr_121213_health_inequalities.pdf.

Barton, H., and M. Grant. 2006. A health map for the local human habitat. The Journal for the Royal Society for the Promotion of Health 126 (6): 252-253.

Bisogni, C., C. Devine, M. Connors, and J. Sobal. 2002. Who we are and how we eat: A qualitative study of identities in food choice. Journal of Nutrition Education and Behavior 34: 128-139.

Bourdieu, P. 1986. The forms of capital. In Handbook of theory and research for the sociology of education, ed. J. Richardson, 241-258. New York: Greenwood.

Bourdieu, P. 1984/1973. Distinction: A social distinction of the judgment of taste. Routledge.

Burchi, F. n.d.. On the relationship among education, development and food security through the capability approach. Thesis. Available at http://dspace-roma3.caspur.it/bitstream/2307/134/1/Tesi\%20di\%20dottorato. FRANCESCO\%20BURCHI.Economia.pdf.

Carpenter, M. 2009. The capabilities approach and critical social policy: Lessons from the majority world?. Critical Social Policy 29(3):351-373.

Clark, D.A., ed. 2006. The Elgar companion to development studies. Cheltenham: Edward Elgar.

Cockerham, W., T. Abel, and G. Lüschen. 1993. Max Weber, formal rationality, and health lifestyles. The Sociological Quarterly 34 (3): 413-428.

Cockerill, M. 2012. Enabling children and young people to flourish: the capabilities approach and its Aristotelian roots. University of Durham: UMI Dissertations Publishing.

Coufopoulus, A. \& Mooney, K. (2012). 'Food, nutrition and homelessness. Guidance for practitioners'. Last accessed March $11^{\text {th }} 2017$ at http://www.qni.org.uk/docs/Nutrition_Guidance_web.pdf.

Daron, N., and A. Drenowski. 2015. Contribution of food prices and diet cost to socioeconomic disparities in diet quality and health: A systematic review and analysis. Nutrition Reviews $0(0)$ : $1-18$. 
Davison, J., Share, M., Hennessy, M. and Stewart Knox, B. 2015. 'Caught in a 'spiral'. Barriers to healthy eating and dietary health promotion needs from the perspective of unemployed young people and their service providers'. Appetite 85:146-154.

Deneulin, S. 2009. An introduction to the human development and capability approach: Freedom and agency. London, earthscan.

Donald, A. 2009. "Facilitating community action". In Oxford Handbook of Public Health Practice (2009). Oxford University Press.

Donnelly, P. 2007. Public Health in Scotland: the dividend of devolution. In New perspectives in public health, ed. S. Griffiths and D. Hunter. Abingdon: Radcliffe Publishing.

Douglas, F., et al. 2015a. The nature and extent of food poverty. NHS Health Scotland.

Douglas, F., J. Sapko, K. Kiezebrink, and J. Kyle. 2015b. Resourcefulness, desperation, shame, gratitude and powerlessness: Common themes emerging from a study of food Bank use in Northeast Scotland. AIMS Public Health 2 (3): 297-317.

Dowler, E. 2008. Poverty, food and nutrition. In Why money matters : family income, poverty and children's lives, ed. Jason Strelitz and Ruth Lister, $34-43$. London: Save the Children.

Drèze, J. \& Sen, A. 1991. Hunger and public action. Oxford: Oxford University Press.

Friel, S., L. Hattersley, L. Ford, and K. O'Rourke. 2015. Addressing inequities in healthy eating. Health Promotion International 30 (S2): 77-88.

Gombert, K., Douglas, F., McArdle, K. \& Carlisle, S. 2015. 'Reflections on ethical dilemmas in working with socalled 'vulnerable' and 'hard-to-reach' groups: Experiences from the Foodways and Futures project'. Educational Action Research journal 24(4):583-597.

Lambie-Mumford, H. et al. 2014. 'Household Food Security in the UK: A Review of Food Aid'. Available at https:/www.gov.uk/government/uploads/system/uploads/attachment_data/file/283072/household-foodsecurity-uk-executive-summary-140219.pdf.

Lewis, L. 2012. The capabilities approach, adult community learning and mental health. Community Development Journal 47 (4): 522-537.

Love food hate waste Scoland. 2016. 'The facts about food waste'. Last accessed March $11^{\text {th }} 2017$ at http://scotland.lovefoodhatewaste.com/content/about-food-waste- 0 .

Lumby, J., and M. Morrison. 2009. Youth perspectives: Schooling, capabilities frameworks and human rights. International Journal of Inclusive Education 13 (6): 581-596.

Marmot, M. et al. 2010. 'Fair society healthy lives. The marmot review'. Last accessed March $11^{\text {th }} 2017$ at http://www.instituteofhealthequity.org/projects/fair-society-healthy-lives-the-marmot-review.

McKelvie, G. 2012. 'Malnutrition link to deaths.' Last accessed March 11th 2017 at http://www.heraldscotland. com/news/health/malnutrition-link-to-deaths.18930204.

National Health Service (NHS) 2014. 'Equalities and health inequalities'. Last accessed March $11^{\text {th }} 2017$ at http://www.healthscotland.com/equalities/health-inequalities/index.aspx.

Oxford Poverty and Human Development Initiative (OPHDI) n.d.. 'The Capability Approach and Human Development'. Report by Alkira, S. Available at http://www.ophi.org.uk/wp-content/uploads/OPHIHDCA-SS11-Intro-to-the-Capability-Approach-SA.pdf.

Perry, R. 2013. "A study of Diet \& Nutrition in young homeless people before \& after supported accommodation at Aberdeen foyer". (unpublished).

Pogge, T. n.d.. 'Can the capabilities approach be justified?' Available at http://philosophyfaculty.ucsd. edu/faculty/rarneson/Courses/poggel capability.pdf.

Pritchard, A. 2012. Health, Power, Justice and Truth. Review of Venkatapuram, S. Health Justice: An Argument from the Capabilities Approach. Journal Of Evaluation In Clinical Practice 18 (5): 1116-1118.

Robeyns, I. 2003. 'Capabilities approach: An interdisciplinary introduction'. University of Amsterdam. Available at http://commonweb.unifr.ch/artsdean/pub/gestens/f/as/files/4760/24995_105422.pdf.

Ruger, J. 2003. Toward a theory of a right to health: Capability and incompletely theorized agreements. Yale Joural Law Humanities 18 (2): 3.

Scott-Samuel, A. \& Smith, K. 2015. 'Fantasy paradigms of health inequalities: Utopian thinking?' Social Theory and Health 13:418-436.

Sen, A. 1979. Equality of what? Stanford University: Tanner Lectures on Human Values. Available at http://tannerlectures.utah.edu/_documents/a-to-z/s/sen80.pdf.

Sen, A. 1982. Poverty and famines: An essay on entitlement and deprivation. New York, Oxford: Clarendon Press Oxford University Press.

Sen, A. 1985. Commodities and capabilities. Oxford India Paperback.

Sen, A. 1992. Inequality Re-examined. Oxford: Clarendon Press. New York, Cambridge, MA: Russell Sage Foundation, Harvard University Press.

Sen, A. 1999. Development as freedom. Oxford: Oxford University Press.

Sen, A. 2005. Human rights and capabilities. Journal of Human Development 6 (2): 151-166. 
Sen, A. 2010. The idea of justice. London: Penguin.

Simon, J., et al. 2013. Operationalising the capability approach for outcome measurement in mental health research. Social Science \& Medicine 98: 187-196.

The Scottish Government 2010. 'Preventing Overweight and Obesity in Scotland. A Roadmap towards a healthy weight.' Last accessed March $11^{\text {th }} 2017$ at http://www.scotland.gov.uk/Resource/Doc/302783/0094795.pdf.

The Scottish Government 2015. 'Poverty in Scotland'. Last accessed March $11^{\text {th }} 2017$ at http://www.gov. scot/Resource/0050/00502217.pdf.

United Nations Development Program (UNDP) 2012. 'A human development and capability approach to food security: Conceptual framework and informational basis' Report by Burchi, F. \& De Muro, P.. Available at http://www.africa.undp.org/content/dam/rba/docs/Working\%20Papers/Capability\%20Approach\%20 Food\%20Security.pdf.

Venkatapuram, S. 2007. 'Health and justice: The capability to be healthy'. Dissertation. King's College, University of Cambridge. Available at https://www.repository.cam.ac.uk/bitstream/handle/1810/224951 /venkatapuram_PhD_healthcapability.pdf? sequence $=1$.

Venkatapuram, S. 2011 . Health justice: An argument from the capabilities approach. Cambridge: Polity Press.

Venkatapuram, S. 2013. Health, vital goals and central human capabilities. Bioethics 27 (5): 271-279.

Walker, M. 2005. Amartya Sen's capability approach and education. Educational Action Research 13 (1): $103-110$.

Weaver, R., M. Lemonde, P. Naghmeh, and W. Goodman. 2014. Health capabilities and diabetes self-management: The impact of economic, social, and cultural resources. Social Science \& Medicine 102: 58-68.

Weber, M. 1978. Economy and society: An outline of interpretive sociology. Berkeley: University of California Press.

Wilkinson, R., and K. Picket. 2010. The spirit level. Why equality is better for everyone. UK: Penguin Books Limited.

World Health Organisation (WHO) 2005. 'Action on the social determinants of health'. Last accessed March $11^{\text {th }}$ 2017 at http://www.who.int/social_determinants/resources/action_sd.pdf.

World Health Organization 1986. The Ottawa Charter for Health Promotion. Geneva, Switzerland: WHO; 1986 Nov 21 Available from: http://www.who.int/healthpromotion/conferences/previous/ottawa/en/index.html. 